\title{
EL DISCURSO DESINCRETIZADOR Y WOMANISTA DE GEORGINA HERRERA: HACIA UNA DESCOLONIZACIÓN DE LA ESPIRITUALIDAD DE LA MUJER NEGRA CUBANA
}

\section{Georgina Herrera's Womanist and unsyncretic discourse: Toward a Spiritual Decolonization of the Afro-Cuban Woman}

\author{
Ana Zapata-Calle \\ zapatacalle@yahoo.es \\ University of Wet Georgia-Carrolton - Estados Unidos
}

Recibido: 11-06-2016

Aceptado: 20-04-2017

\section{Resumen}

El propósito de este artículo es usar la poesía de Georgina Herrera para deconstruir la tradición de la santería que considera la religión yoruba como una ramificación del catolicismo y no como una religión universal. Georgina Herrera refleja en sus poemarios África (2006) y Gatos y liebres o libro de las conciliaciones (2010) el nuevo discurso afro-cubano que apuesta por una heterogeneidad religiosa que emerge en Cuba a finales de los años ochenta. Además, la poeta aboga en su poesía por el derecho del liderazgo religioso de la mujer afro-cubana, recuperando las practicas yorubas ortodoxas y el papel activo de las mujeres en sus rituales.

Palabras Clave: Georgina Herrera, mujer negra, santería, desincretización, espiritualidad, poesía afro-cubana, Yoruba, descolonización, religión, womanismo.

\begin{abstract}
The purpose of this article is to use Georgina Herrera's poetry in order to deconstruct the tradition of santería that considers the Yoruba religion under the wing of Catholicism and not as a universal religion. Georgina Herrera reflects in her books of poems África (2006) and Gatos y liebres o libro de las conciliaciones (2010) the new Afro-Cuban discourse of religious heterogeneity that emerged in Cuba at the end of the eighties. Furthermore, the poet advocates for the right to leadership of Afro-Cuban women recovering the orthodox Yoruba practices and the active role of women in their rituals.
\end{abstract}

Keywords: Georgina Herrera, black woman, syncretism, spirituality, Afro-Cuban poetry, Yoruba, decolonization, religion, womanism. 


\section{Introducción}

Georgina Herrera es una de las poetas afrocubanas más reconocidas dentro de Cuba, junto a otras como Nancy Morejón, Excilia Saldaña o Soleida Ríos. Sobre su infancia ella misma explica en su testimonio narrativo Golpeando la memoria (2005) cómo pudo superar sus limitaciones materiales y abrirse camino en el mundo de las letras, a pesar de las dificultades que experimentó al proceder de una familia negra muy humilde y no letrada. La escritora nació en 1936 en Jovellanos y, con la misma ilusión que muchas otras jóvenes afrocubanas, llegó a La Habana en 1956, donde se instaló con sus tías ${ }^{1}$. Una de sus mayores aspiraciones era abrirse camino en su temprana carrera literaria, ya que algunos de sus poemas juveniles habían sido publicados en periódicos de La Habana tales como el diario El País. Para llevar a cabo sus metas, estudió secretariado público en una academia nocturna y siguió escribiendo. Con la llegada de la Revolución en 1959, la joven poeta supo aprovechar las nuevas oportunidades educativas y laborales y, después de un tiempo, logró vivir de su escritura de novelas radiofónicas trabajando para Radio Progreso.

A lo largo de su vida, Georgina Herrera ha producido poesía, teatro, prosa y algún guión cinematográfico. De su trabajo creativo en la radio ella misma afirma que "la temática para los dramatizados ha dependido de la problemática político-social del momento, y ella ha condicionado las novelas, teatros y cuentos que han salido al aire" (Rubiera Castillo, 2005: 114). Sin embargo, la poesía siempre ha sido para ella el refugio en el cual se ha expresado con más libertad, donde se ha escapado como una cimarrona que huye al monte ${ }^{2}$.

En este análisis se toman algunas composiciones de los poemarios Gatos y liebres o libro de las conciliaciones (2010) y de África (2006), para exponer cómo Georgina Herrera encuentra en la espiritualidad afrodescendiente su refugio como mujer, alejada de la santería y del catolicismo practicado en Cuba. En busca de su liberación espiritual, la poeta participa con sus versos en la creación de un nuevo discurso religioso desincretizador que trata de separarse del catolicismo y que surge en Cuba desde finales de los años ochenta. Este discurso ha evolucionado hasta hoy desarrollando una vertiente femenina que defiende el papel de la mujer en la religión afrodescendiente. Para mostrar esta progresión, este artículo se divide en dos partes. Con los poemas tomados de Gatos y liebres se presenta el discurso desincretizador inicial y con el poemario

\footnotetext{
${ }^{1}$ Sobre su experiencia laboral durante los primeros años de su estancia en La Habana Georgina Herrera habla en el documental del director Jean Weisman, From maids to compañeras (1998).

${ }^{2}$ El símil del cimarronaje lo desarrolla la poeta en varios de sus poemas. Esta imagen la retoma Juanamaría Cordones-Cook en el documental Cimarroneando con G.H. (2011) y en el artículo "Georgina Herrera: una cimarrona contemporánea" (2012).
} 
África, parte central de este análisis, se aboga por una reivindicación womanista $^{3}$ en torno a cuestiones espirituales, donde se analiza la opresión simultánea de género y raza dentro de la propia Regla de Ocha y donde se propone un nuevo orden femenino no excluyente que vuelve a una espiritualidad africana más ortodoxa.

Georgina Herrera supera el patriarcado bajo el que se organizan los cultos afrocubanos de la Regla de Ocha, argumentando la conexión directa entre un poder superior y la mujer negra, sin que esta tenga que recurrir a un intermediario sólo por ser mujer. De esta manera, en un intento de descolonizar el imaginario religioso, la autora responde simultáneamente al eurocentrismo y al patriarcado proponiendo la práctica de una religión yoruba desincretizada ${ }^{4}$ y postpatriarcal.

\section{La desincretización de la religión afrocubana en Gatos y liebres o libro de las conciliaciones}

Después de décadas de ilegalidad de las religiones en Cuba bajo la ideología marxista, en 1992 se ofrece un marco legal para los practicantes y creyentes de todas las religiones, incluyendo la aceptación de las prácticas religiosas afrocubanas. Esta apertura hacia las religiones comenzó con la gran crisis tras la caída del Muro de Berlín en 1989. Para 1991, ya se había creado la Asociación Cultural Yoruba en el centro de la Habana donde se rinde culto a la Regla de Ocha y se mira hacia la ciudad nigeriana de Ilé Ifé como ciudad sagrada (Ayorinde, 2004: 224).

Con esta nueva aceptación religiosa, algunos de los creyentes yorubas buscan una reafricanización o yorubización de la espiritualidad afrocubana. El objetivo es deconstruir la tradición impuesta que acepta la religión Yoruba sólo en su vertiente sincrética de la llamada santería, como una rama del catolicismo, y no como una religión universal separada del catolicismo. Así se ha considerado en las visitas de los Papas a Cuba, ya que los protocolos han excluido a los representantes yorubas por considerar esta religión como folklore o como ritos satánicos (Orozco y Bolívar, 1998: 320-21)5 .

\footnotetext{
${ }^{3}$ Se sabe que la poeta es conocedora de la obra de Alice Walker de la que procede el término de "womanismo", ya que ella misma admite ser una gran lectora de su obra en una entrevista concedida a Linda S. Howe (2003: 145). Aunque estas lecturas son sólo un complemento a un womanismo que Georgina Herrera basa en la experiencia y lucha de la mujer cubana dentro de su comunidad religiosa, como se verá en el apartado final.

${ }^{4}$ Rubén Zardoya lanzó el término de "desincretización" de la santería y en el blog del colectivo Ifá Esbu Omó Iré se ha comentado ampliamente su artículo "Adiós al sincretismo: Minuta sobre la transculturación de la religión yoruba en Cuba." (1996). Una de las comentadoras es Rosa María de Lahaye Guerra, quien cuestiona esta terminología en su artículo “¿Adiós al sincretismo?” (2010).

${ }^{5}$ Román Orozco y Natalia Bolívar dedican el capítulo "Somos mestizos" de su libro Cubasanta (1998) al enfrentamiento entre credos que se generó con la primera visita del Papa tras la reapertura religiosa cubana.
} 
Partiendo de esta falta de reconocimiento, hay un intento de volver a los rituales y mitos originales con el fin de desarrollar una práctica más ortodoxa de la experiencia religiosa yoruba. De esta manera lo explica Fernández Robaina:

"En la santería el movimiento de la yorubización ha sido llevado a cabo principalmente por los babalawos, entre los que se encuentra el babalawo Antonio Castañeda, presidente de la Asociación Cultural Yoruba de Cuba. Dicha asociación propugna también el rechazo al sincretismo y trata de construir nuevas tradiciones [...] De igual modo aconseja no mencionar a los orishas con los nombres católicos sincretizados con ellos" (2009: 93).

Christine Ayorinde describe en "Santería in Cuba: Tradition and Transformation" el proceso de búsqueda de una mayor ortodoxia ante la necesidad de rehabilitar lo que todavía en los años noventa era denigrado como sincrético y considerado inferior a las religiones universales:

"Esto abogaba por enfatizar las raíces africanas de la santería y reconocer la ortodoxia en los rituales a través de una vuelta a la liturgia de los cultos de los orishas nigerianos del corpus de Ifá. Los elementos sincréticos (católicos romanos y espiritistas) debían ser eliminados de las prácticas. El término "Regla de Ocha-Ifá" reemplazaría el de "santería", y los de "babalocha/iyalocha" serían usados en vez de "santero/santera". Los orishas no iban a ser nombrados más por los nombres de los santos católicos" $"$ " (2004: 224).

La desvinculación del catolicismo y el proceso de yorubización no han carecido de polémica en Cuba. Este discurso ha sido acompañado de una controversia en la que se han barajado términos como el de la "cruzada" contra el sincretismo o la de "descolonización" del catolicismo?. Este discurso ha calado también en la literatura afrocubana, siendo Georgina Herrera una de las escritoras que deja testimonio de este cambio a nivel religioso, social y cultural.

La idea de cruzada en defensa de la yorubización queda recogida por la poeta en Gatos y liebres o libro de las conciliaciones, en cuyo prólogo afirma que para ella la poesía "es la guerra santa que libramos todos los días; sus pies, siempre descalzos, en la tierra, y su cabeza, ascendiendo desde el trino y la flor, hasta los astros" (2009:5). Con la alusión a los pies y a la cabeza, Georgina Herrera incluye ya desde el prólogo de su libro la idea del ritual conocido como "pata y cabeza”. Según Silvina Testa, este ritual consiste en recibir al ángel de la guarda (cabeza)

\footnotetext{
6 "This advocated emphasizing the African roots of Santeria and recovering orthodoxy in ritual through a return to the liturgy of the Nigerian orisha cults and the Ifá corpus. Syncretic (Roman Catholic and spiritist) elements were to be eliminated from the practice. The term 'Regla de Ocha-Ifa' would replace 'Santería,' and 'babalocha/iyalocha' would be used instead of 'santera/santero.' Orishas were no longer to be referred to by the names of Catholic saints" (2004: 224).

${ }^{7}$ La SECNEB (Sociedade de Estudos da Cultura Negra no Brasil) organizó la primera conferencia sobre la tradición cultural de los Orishas en 1981, en Ilê Ifé. Su propósito era reunir a representantes religiosos africanos con otros de la diáspora americana. En 1983 se organizó la segunda conferencia internacional en el Salvador donde se habló de la "Cruzada contra el sincretismo religioso" o "acto de descolonización contra el catolicismo" (Parés, 2004: 201-2).
} 
y a los santos guerreros (pies) (Testa, 2004, citado por Fernández Robaina, 2009: 90). Si bien el ritual de "pata y cabeza" era utilizado antiguamente y se dejó de practicar, con la vuelta a la ortodoxia se reivindica y se vuelve a él. Fernández Robaina explica que "el llamado proceso de la reafricanización [...] se observa ya a finales de la década de los ochenta y se incrementa en los inicios de la década de los noventa con la demanda y reiniciación de nuevos santeros mediante el estilo de pata y cabeza" (2009: 90).

La descolonización espiritual parece necesaria para recuperar la dignidad humana del afrodescendiente, eliminando la subordinación a la superioridad del sistema católico. En Gatos y liebres, Georgina Herrera lanza la propuesta de la heterogeneidad religiosa, donde tanto el cristianismo como la Regla de Ocha-Ifá cuenten con un espacio divino por separado, dentro de la misma isla-nación. De esta manera, en “Aviso a los que viven en Caná” (2010: 27), la voz poética se siente capaz de organizar a su pueblo por su cuenta para sobrevivir a la hambruna ${ }^{8}$, sin la ayuda de los milagros divinos. Nombrar a los afrocubanos como habitantes de Caná parece aludir al hecho de que estos están colonizados por el cristianismo, es decir, que viven en el espacio católico, aunque se sientan abandonados por el Dios occidental, como Cristo pensó que su padre lo había hecho en el momento de su mayor tormento ${ }^{9}$ :

\section{"Canaenses:}

Hasta que dios regrese

(si es que vuelve)

no habrá milagros $[\ldots]$

Así que, mientras vuelve, por si tarda,

hagamos redes, barcas,

ganemos tiempo" (Herrera, 2010: 27).

Para recuperarse de la situación penosa en la que viven esperando milagros que nunca llegan, la voz poética propone organizarse independientemente del sistema espiritual y económico imperante, proponiendo la desincretización y el trabajo para superar la crisis.

La salida del sistema católico se justifica en "Dios de mi casa y de mi sangre: Olofi" (Herrera, 2010: 41), por la superficialidad del sincretismo religioso. En los dos primeros versos, la voz poética se proyecta orgullosa de pertenecer a una familia de descendencia directa africana:

\footnotetext{
"Familia negra en la que no hubo

mezcla alguna:

negros los ojos, la piel, el pelo duro;

y el alma, pura,

casi salvaje, porque
}

\footnotetext{
${ }^{8}$ Este poema se escribe en 1990, según aparece indicado por la poeta al final del texto, cuando Cuba se enfrenta a carencias drásticas con la llegada de la gran crisis del llamado Periodo Especial.

${ }^{9}$ Se alude aquí a la frase bíblica de Cristo: “¿Padre, por qué me has abandonado?”.
} 
el origen era la selva" (Herrera, 2010: 27).

La descripción de la familia no se detiene en los rasgos físicos, sino que incluye el alma, asociada con la selva y con Olofí. No niega, sin embargo, el contacto con el catolicismo, aceptado por los familiares superficialmente y por lástima, con condescendencia y a la fuerza. La imposición religiosa es recordada con violencia en el hogar familiar:
“¿Qué pobreza de hogar!; en las paredes
solo un retrato. Colgaba un Cristo rubio,
impuesto
sobre la piel a quemaduras desde
quien sabe cuándo.
Y así, las cosas
no entran o entran mal.
pero a ese pobre hubo que amarlo,
nos daba pena verlo $[\ldots]$
casi por lástima lo aceptamos $[\ldots]$
pero en la sangre, a su albedrío" (Ibídem).

La alusión al libre albedrío remite al principio cristiano por el cual el Dios católico ha concedido al ser humano la facultad de tomar sus propias decisiones, en contra de un destino preconcebido. La voz poética sigue esta idea cristiana para reclamar a otro dios y para establecer su derecho de continuar con las prácticas religiosas de sus ancestros africanos. Por ello, se reclama a Olofí ${ }^{10}$ como "un solo rey universal" (Ibídem). Este dios rebelde y en constante actividad es el que parece correr por su sangre, "frenando potros o soltándolos,/ fundiendo soles, apretando lunas,/ saliendo, entrando y, como el viento, nunca/ tranquilo" (Ibídem).

Por otra parte, en el poema "Al palacio real llegan mensajes" (Herrera, 2010: 38-39), hay una clara división entre el Dios occidental y Olofí, regidores de dos universos religiosos diferentes. Los creyentes de estos dos sistemas están presentados mediante dos pronombres, en un enfrentamiento entre un "tú" y un "yo". La voz poética, usando el pronombre en primera persona, defiende su fe en Olofí y denuncia las injusticias y abusos que su dios y la comunidad yoruba han sufrido a manos del dios de su interlocutora, nombrada como un "tú" al que se dirige con un tono acusador. La voz poética recrimina a la "Reina Madre" y a su "heredera al trono" que aquí se interpretan como la Virgen María y su creyente católica-, por su complicidad con los abusos cometidos por los conquistadores y esclavistas del pasado y la ostentación de sus privilegios. Les censura el hecho de que sigan creyendo en la justicia divina de su Dios sin cuestionársela, ya que en su nombre se ha denigrado al pueblo negro. Además, cuando la voz poética le pide justicia al Dios católico por los delitos cometidos en su nombre, éste no responde,

\footnotetext{
${ }^{10}$ Olodumare u Olofí son los nombres del dios supremo en la religión yoruba, considerado como el dueño del cielo y el creador de la energía y el universo.
} 
por lo que se dirige entonces a su creyente heredera y lo tilda de cobarde: "Ahora, tu dios/— todo lo hicieron en su nombre—- no da la cara, no asoma la cabeza" (Herrera, 2010: 39). Tras esto, afirma que uno de los prodigios de Olofí es poder juzgar al opresor católico que aún hoy sigue disfrutando de los privilegios heredados.

"su dedo índice, oscuro, fuerte, limpio,

es quien señala

cómo aún

la sangre de los míos cuelga de tus orejas" (Herrera, 2010: 27).

El racismo persistente, bien sea a nivel religioso o de otro tipo, queda implícito en el adverbio "aún" que incluye la poeta en un verso de sólo dos palabras para realzar su importancia. Las ideas de desincretización y de heterogeneidad son claras, porque los creyentes de un Dios y de otro están separados entre un "tú" y un "yo" en guerra, siendo la fiel de Olofí quien pide justicia por el abuso cometido contra su comunidad religiosa.

\section{La yorubarización womanista en África}

La palabra "África" con la que Georgina Herrera titula el poemario parece responder al acercamiento que se está llevando a cabo en Cuba hacia las raíces culturales y las prácticas religiosas ortodoxas africanas desde finales de los años ochenta ${ }^{11}$. Herrera conecta la palabra con un mundo lleno de una recuperada cultura y religión. Rogelio Martínez Furé explica en el prefacio de Poesía yoruba que "la esclavitud dejó toda una estela de prejuicios, haciendo que siempre se mirase hacia el África como la tierra sin historia ni valores" (Barquet, 2011: 525). Herrera contribuye a cambiar este imaginario negativo y de vacío cultural desde el punto de vista femenino. Para ello, reclama un espacio digno para la mujer dentro del proceso de reafricanización cultural y yorubización espiritual, revaloriza sus valores éticos y morales y deja constancia de su contribución en la historia de Cuba.

En su acercamiento hacia las cuestiones de género, Georgina Herrera responde en África a lo que Joyce Ann Joyce (1999) llama "African-Centered Womanism". En este capítulo se desarrolla la hipótesis de que la poeta une dos concepciones culturales como son el afrocentrismo, que abarca a todos los afrodescendientes, y el womanismo, que valora a la mujer negra dentro de sus comunidades sacándola del patriarcado. De esta manera, el imaginario espiritual y religioso presentado en África se constituiría como la búsqueda por parte de la mujer negra de un espacio de protección y libertad independiente tanto del catolicismo, como del patriarcado de la Regla de

\footnotetext{
${ }^{11} \mathrm{El}$ discurso de desincretización comienza en los ochenta, pero se incrementa en los años noventa con la mayor aceptación política de las prácticas religiosas en Cuba (Fernández Robaina, 2009: 90).
} 
Ocha-Ifá. Para ello, Herrera propone una neoafricanización cultural que recupere el papel específico de liderazgo que disfrutaban las mujeres en la religión yoruba ortodoxa, funciones que aún hoy siguen ejerciendo las africanas en algunas comunidades tradicionales con el cargo de iyanifá o sacerdotisa de Ifá.

La exclusión y la subordinación de la mujer negra en las prácticas religiosas afrocubanas son comportamientos que han sido aceptados desde la esclavitud en América. Por el largo proceso de sincretización con los valores patriarcales del catolicismo, las funciones espirituales de las mujeres negras como líderes se perdieron en los cabildos establecidos en Latinoamérica, sin tener en cuenta muchos de los mitos y prácticas originales yorubas. El proceso de yorubización y desincretización que emerge en Cuba a finales del siglo XX continúa con estas mismas pautas discriminatorias. De las ramas religiosas afrocubanas, las sociedades secretas masculinas abakuá no aceptan mujeres en su composición, mientras que la Regla de Ocha y la Regla Conga permiten que participen en los ritos religiosos con un papel subordinado al del máximo sacerdote o babalawo. Las mujeres pueden llegar a ser iyalochas (santeras) pero no tienen la opción de formarse en los secretos de la adivinación para ocupar la categoría de iyanifá, sacerdotisa de Ifá, el equivalente femenino del babalawo ${ }^{12}$. De hecho, un babalawo yoruba africano decidió iniciar a algunas mujeres americanas en la profesión de iyanifá ${ }^{13}$ en 1985 en la localidad de Oshogbo, Nigeria, y muchos babalawos latinoamericanos condenaron este hecho (Murrell, 2010: 122).

Tomás Fernández Robaina recoge el debate y la reflexión que afloró en Cuba acerca del papel de la mujer en la santería en 1990:

\begin{abstract}
"No todos los santeros y no todos los babalawos simpatizaron con la posibilidad de que las mujeres pudieran consultar con el ekuele [...] No han sido suficientes las explicaciones de que esa tradición existía y existe entre los practicantes de la religiosidad yoruba en sus tierras ancestrales [...] Ha pesado más la costumbre y la tradición, la existencia del machismo y el dominio del poder religioso en manos de los hombres" (Robaina, 2009: 94).
\end{abstract}

En el diálogo establecido en la primera conferencia de estudios afrocubanos convocada por la Casa de África Fernando Ortiz en Santiago de Cuba, la santera puertorriqueña Ángela Jorge se quejó de la jerarquización de las prácticas afrocubanas y de la subordinación de las iyalochas. Ella protestaba por el hecho de que no se les permitiera realizar determinados rituales ni tampoco se les facilitara la formación para llevar a cabo ciertas actividades de mayor prestigio o

\footnotetext{
${ }^{12}$ Desde 1568 se habían creado cabildos organizados y jerarquizados que reunían a los esclavos de las mismas tribus. La jerarquía patriarcal establecida ha permanecido hasta hoy en la santería donde el máximo poder es dado a un babalawo, conocido como sacerdote de Ifá. Le siguen en orden descendente los babalochas (santeros) y las iyalochas (santeras) y bajo ellos están los eriaté, los obbá y otros (Argüelles Mederos, 1998: 33).

${ }^{13}$ Las dificultades que enfrenta una Iyanifá en Latinoamérica quedan plasmadas en el testimonio escrito por la Iyanifá Ileana S. Alcamo en su libro The Challenge. Growing Within the Orisa Community (2002), traducido al inglés por Oluwo Cris Alcamo.
} 
conocimiento. Por su parte, Daisy Rubiera Castillo ${ }^{14}$, "formuló de manera tajante que esa era una forma abierta de discriminación femenina" (Fernández Robaina, 2007: 188) ${ }^{15}$.

En el poemario África, Georgina Herrera dota a la mujer de una presencia fuerte y positiva y no subordinada en el espacio espiritual. Da voz y vida a las afrodescendientes y a orishas como Oyá, Ochún y Yemayá, que presenta como modelos de actividad, de lucha y de poder, desligándose de la imagen de debilidad y de sacrificio que aparece en los odú (mitos) patriarcales y sexistas. Si en Granos de sol y luna los valores de estas orishas aparecían como alternativos a los occidentales en un intento de desincretizarse de la imagen mariana, en África la trinidad femenina de diosas ya aparece desligada de occidente y del patriarcado, postulando con ellas un discurso womanista. Estas diosas surgen africanizadas, exponiendo otra manera de ser con un nuevo sentido de independencia y libertad. La poeta ofrece el testimonio de este cambio de perspectiva hacia el womanismo que trata de educar a las mujeres para que sean las protagonistas de sus propias historias, ejemplos de moralidad y vitalidad, y no las acompañantes, servidoras o víctimas de sus hombres.

El continente africano se ve en África como una tierra madre mítica y sagrada, a la que se llama "Nuestra Antigua Señora Violentada" (2006: 7) como si de una Virgen María se tratara, pero violada. La mujer negra violentada se constituye en el mundo poético de Herrera como la base del mito fundacional de la Afro-Cuba, al igual que la Malinche ${ }_{16}$ lo es de México. La escritora compara a la mujer negra maltratada en tierras americanas con la mujer indígena al traer a colación el caso de una niña indígena peruana acusada de impúdica por la ciencia, al dar a luz a un hijo fruto de una violación (Herrera y Rubiera, 2005: 65). Con ello, Georgina Herrera cuestiona el concepto de moralidad de origen occidental que ampara al violador y trata de devolver la dignidad tanto a la mujer americana violada como a sus hijos. Al proponer la nueva moralidad womanista, la mujer negra deja de verse como fuente de pecado llena de estereotipos negativos transformándose en un manantial de vida e inspiración para otras mujeres.

La idea de la vuelta a África en su ortodoxia religiosa está presente en "Oyendo hablar al viejo Owení" (Herrera, 2006: 7-8), en donde el viaje no se entiende en un sentido geográfico ni físico, sino espiritual. La voz poética recuerda el mensaje escuchado por ella desde el vientre materno que le fue transmitido por Owení a través del lenguaje sagrado de los tambores:

"El viejo Owení hablaba

desde el tan tan espeso del tambor.

$[\ldots]$

\footnotetext{
${ }^{14}$ Directora de la Casa de África Fernando Ortiz en Santiago de Cuba cuando se celebró la conferencia.

${ }^{15}$ En su artículo "La mujer en la Regla de Ocha: una mirada de género" (1999), Daisy Rubiera Castillo denuncia la desigualdad entre santeros y santeras, el sexismo de los odú manipulados, y la prohibición de que la mujer sea sacerdotisa.

${ }^{16}$ La Malinche fue una joven indígena que acompañó a Hernán Cortés a lo largo de la conquista del Imperio azteca y desempeñó a su servicio la función de intérprete y traductora de poblaciones indias. A pesar de haber sido vendida por su propio pueblo como esclava a los conquistadores, ha pasado a la historia como traicionera de su pueblo, a la vez que la originaria del mismo, por haber tenido un hijo mestizo con Cortés.
} 
Hacía reclamo, urgía su regreso [...]

Si no vuelvo

- se iba acostumbrando-

hazlo tú" (Herrera, 2006: 7).

El viejo Owení es un hombre que posee el conocimiento del lenguaje sagrado que se expresa mediante la percusión del tambor y que se lo transmite a la niña que está por nacer. Nathaniel Samuel Murrell explica que el ritmo de los tambores refleja el pálpito de la religión y provee un instrumento vital para poderse comunicar con los orishas (Murrell, 2010: 133). La voz poética de “Oyendo hablar al viejo Owení" escucha el tambor desde que era sólo "un latido, una advertencia, una justicia/ por llegar" (Herrera, 2006: 7). La niña percibe el mensaje sagrado a pesar de su género femenino, enfrentándose a la opinión de las comunidades religiosas afrocubanas que consideran a la mujer incapaz de aprender el ekuele (lenguaje sagrado). En contra de esta convención social, la niña parece ser la elegida por los orishas para transmitirle el conocimiento divino. Pero la voz poética adulta reacciona con dolor al saberse con la misión sagrada y no poder cumplirla por los impedimentos comunitarios: "volver a casa ha sido otro asunto,/ un fuego desgarrado que hago arder" (Ibídem: 8). El "yo", definido como "una justicia/ por llegar" (Ibídem: 7), abre una polémica donde los ánimos arden como un "fuego desgarrado", para que pueda restablecerse su derecho a aprender el lenguaje sagrado y poder cumplir con ello el designio divino en suelo cubano.

La búsqueda del cambio de un sistema patriarcal a otro más inclusivo lo expresa Georgina Herrera al hablar de su poema "Oriki para las negras viejas de antes" en el ensayo comprendido en el libro Afrocubanas ${ }^{17}$. La poeta cuenta la transición que vivió de niña cuando murió su abuelo, quien había sido el centro en las reuniones que se hacían para contar historias de todo tipo. Tras su muerte, comenzaron a llegar mujeres conocidas del pueblo que "fueron alzando cada vez más la voz, perdiendo ese respeto que el abuelo inspiraba o, más bien imponía, porque solamente él, machista sin saberlo, pero hasta la médula, era dueño de la palabra" (Herrera, 2011: 221). Con esta anécdota, que también se recoge en Golpeando la memoria (Herrera y Rubiera, 2005: 82), la autora da testimonio del cambio que se produjo en su familia en cuanto a la posesión de la palabra en la trasmisión oral de las historias y las leyendas familiares. Georgina Herrera muestra su respeto hacia las negras viejas en el papel de transmisoras del conocimiento y recupera su función de líderes culturales. Como explica Teresa Prados-Torreira acerca de la espiritualidad durante la esclavitud, las mujeres negras tomaron a menudo la posición de líder espiritual, como un papel natural para ellas. Sus trabajos en las plantaciones como cocineras, parteras, y enfermeras, les dieron una autoridad incuestionable sobre la medicina alternativa o el poder dañino de ciertos alimentos, hierbas y plantas. Eso también las proveyó de autoridad como doctoras (2005: 32).

\footnotetext{
${ }^{17}$ Rubiera Castillo y Martiatu Terry (2011).
} 
Como parte de este poder recuperado por las mujeres negras que llenaron de historias la infancia de la niña que era Georgina Herrera, ellas decidieron declararla "lucumisa" 18 , considerándola heredera de la palabra sagrada yoruba. Esta anécdota es registrada en el poema "Ibu Sedi" (Herrera, 2010: 18), en el que la voz poética es elegida entre muchos familiares: "Tú, son lucumisa", estableciendo un mundo femenino capaz de dirigirse a sí mismo y elegir a aquellas mujeres destinadas a la comunicación divina y a la continuación del legado yoruba. Al recuperar la memoria de las negras viejas, también se produce un acercamiento entre África y Cuba, ya que algunas de estas mujeres habían sido esclavas y aún contaban historias traídas de África.

La identificación entre África y la diáspora americana se percibe a través de la metáfora repetitiva de los espejos. El poema más conocido en que esta imagen aparece es en "Primera vez ante el espejo" (Herrera, 2006: 18-19). La voz poética se ve reflejada en la cabeza de una terracota africana, cuyo parecido le hace sentir como si estuviera renaciendo: "es que vuelvo a nacer. / Esta que miro soy yo, mil años antes o más, / reclamo ese derecho" (Herrera, 2006: 18). Este renacer surge al compararse con la imagen de una mujer africana ubicada temporalmente antes de la travesía. Se podría decir que la voz poética se considera hija del África ancestral y, al renacer de ella, reclama el derecho del reencuentro con el pasado espiritual africano. Parece cumplirse aquí la misión transmitida por el viejo Owení, ya que se viaja mediante la identificación con la terracota a un tiempo en el que la religión yoruba no tenía aún contacto con la cristiana, y a un mundo antiguo africano femenino y pre-esclavista que libera a la mujer negra cubana de los prejuicios occidentales originados en la sociedad colonial. En Golpeando la memoria, la autora cuenta la anécdota de la que parte éste poema. Ella estaba en casa del etnólogo Rogelio Martínez Furé y se vio reflejada en una terracota, al igual que reconoció el parecido de otras personas con diversas máscaras, como si su descubrimiento fuera un renacer colectivo:

"miré una máscara africana de las que él tiene y me pareció que era mi doble. Miré otras y comencé a encontrar parecido con otras personas negras conocidas. Ese fue el día en que me hice consciente plenamente de mi identidad racial. Sentí y disfruté un tremendo orgullo por mis antepasados" (Herrera y Rubiera, 2005: 82).

Aunque esta anécdota es autobiográfica, tiene una repercusión plural. En un sentido simbólico, este hecho podría reflejar el fenómeno de la yorubización en la Cuba de finales del siglo XX y principios del XXI. Así, la voz poética del poema "Primera vez ante el espejo" se interpretaría como la voz testimonial del discurso colectivo, político y religioso contemporáneo. De hecho, tanto Rogelio Martínez Furé como Georgina Herrera, así como otros intelectuales, están contribuyendo, como ideólogos, al redescubrimiento del legado cultural africano. La apreciación del mismo hace sentir a la poeta un profundo orgullo por sus antepasados africanos.

Otro factor a considerar en "Primera vez ante el espejo" es la representación del cuerpo de la mujer negra, que deja de enfocarse en las caderas, como se había hecho en la estética negrista.

18 "Lucumí" es el nombre dado al yoruba de Cuba. 
Herrera se centra en la cabeza de la mujer negra y en conceptos abstractos como el amor, las bendiciones, la belleza de sus rasgos y la adoración de su dios. Estos elementos universales y atemporales se equiparan en las dos cabezas, en la de la terracota y en la de la voz poética, de tal manera que el "tú" africano y el "yo" cubano se unifican y se convierten en inseparables:

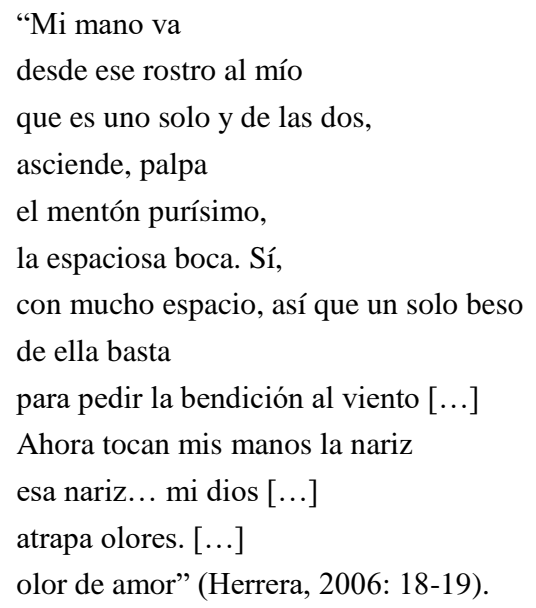

En el plano espiritual, los límites entre el pasado y el presente o entre ancestros y contemporáneos se diluyen. "Primera vez ante el espejo" funciona como un despertar étnico en contacto con la iconografía originaria del África de los ancestros. Sin embargo, el camino para que las mujeres negras creen su propio espacio espiritual no es fácil. Lograr vivir en un entorno cultural y social que permita la igualdad de la mujer negra se presenta como una fase más dentro de la lucha por los derechos humanos.

La composición poética "Despidiendo el duelo de Rosa Parks" ${ }^{19}$ (Herrera, 2006: 15-16) contiene la referencia a una de las activistas más importantes de los años cincuenta en los Estados Unidos $^{20}$. Al despedirse de ella, Georgina Herrera dice adiós a una época en la que mujeres y hombres negros luchaban unidos contra la segregación racial. Como colectivo, todos los integrantes de las comunidades afroamericanas parecen estar unidos por un nosotros inclusivo y por una lucha común: "Nos dedicamos a aplaudirla, a gritar:/ 'Rosa, qué bien, estoy contigo"” (2006: 15). Sin embargo, el presente ya no es igual al de los tiempos de la década de los cincuenta. Tanto en los Estados Unidos como en Cuba se vive una fase distinta en cuanto a la reivindicación de los derechos civiles. La lucha contemporánea en la que la voz poética participa critica el endorracismo y el sexismo dentro de las comunidades negras. En su poesía, Herrera separa la

\footnotetext{
${ }^{19}$ Georgina Herrera le dedica el poema "Despidiendo el duelo de Rosa Parks" a Roberto Zurbano porque durante los días previos a la composición del mismo ellos habían hablado mucho sobre el racismo, la racialidad y el género. Fruto de esta interacción surgió el poema (Zapata-Calle, 18-06-2013).

${ }^{20}$ Danielle L. McGuire explica en At the Dark End of the Street (2011) la participación de Rosa Parks en la preparación y desarrollo del boicot de 1955 , como parte de toda una vida dedicada al compromiso activo de los derechos civiles del pueblo negro estadounidense.
} 
comunidad negra cubana entre un "ellos" y un "nosotras", como se ve en el verso "y ellos, usted sabe quiénes, conectados" (Herrera, 2006: 15). Esta división alude a la interseccionalidad de la discriminación de raza y de género que sufren las mujeres negras en sus comunidades afrodescendientes, así como a la lucha womanista necesaria para su liberación. La escritora es consciente de que se enfrenta a un problema mundial que abarca "los cuatro puntos cardinales" (Ibídem). Sin embargo, aporta su granito de arena y reclama la dignificación de la mujer negra en su comunidad, donde la injusticia no es tan evidente ya que se realiza con "códigos nuevos y secretos" (Ibídem).

No hay que olvidar el desplazamiento y el olvido que sufrió la propia Rosa Parks en el movimiento de los derechos humanos. Como explica Danielle L. McGuire, fueron hombres como Martin Luther King los que asumieron el papel de líderes tras el boicot de 1955 convirtiendo a Rosa Parks en una mujer casi anciana, en una víctima pasiva y en un símbolo solemne, aunque por entonces ella tuviera sólo cuarenta y dos años. De hecho, ni Jo Ann Robinson ni Rosa Parks, las dos mujeres que hicieron posible el boicot, estaban en la reunión donde la asociación Montgomery Improvement surgió y Martin Luther King, Jr. fue elegido como su presidente (McGuire, 2010: 104, 107). Décadas después, el discurso womanista se enfrenta finalmente al silenciamiento y al estado en que ha mantenido el hombre afrodescendiente a las mujeres de su comunidad. En Cuba, el olvido en cuanto a la contribución de la mujer negra en la lucha nacional para conseguir los derechos civiles es comparable al de Rosa Parks y se constata tanto en su falta de representación política en el gobierno cubano como en la no permisividad de su liderazgo religioso ni en el catolicismo ni en la Regla de Ocha.

Tanto la Georgina Herrera en su primer poemario GH (1962) como la activista Rosa Parks estaban comprometida con la lucha contra la discriminación racial y cultural. Décadas después, el objetivo de la poeta es diferente. En el siglo XXI los afrocubanos ya pueden practicar su religión e incluso se permite la desincretización de la santería. Sin embargo, todavía la voz poética femenina del poema se siente desprotegida y sometida por unos hombres alienados a los valores eurocéntricos. En esta situación, las mujeres negras no saben cómo organizarse y se ven a sí mismas como aves que siguen volando "en busca del árbol que las cobije" (Herrera, 2006: 16). Es por esta incertidumbre por lo que se invoca al espíritu de Rosa Parks. Llamarlo insinúa el deseo de llevar a cabo otro boicot colectivo, semejante al convocado por la estadounidense en el pasado, pero dentro de la comunidad afrocubana.

La autora juega con la idea de la identificación entre el pasado y el presente en "Despidiendo el duelo de Rosa Parks", usando el mismo mito del origen del bien y del mal del que ya había escrito en los años sesenta en su poemario $G H^{21}$. En este poemario se produce una disputa entre el cielo y la Tierra y esto pone a la Tierra en peligro de muerte por la escasez de agua. Si en el primer poemario de la poeta, $G H$, aparecían las metáforas de la sequía y de los pájaros que se rompían las alas cuando caían en su intento imposible por llegar al cielo para atraer la lluvia, en ${ }^{21}$ Mercedes Cros Sandoval explica el mito del origen del bien y del mal en su libro La religión afrocubana
(1975), en el capítulo X bajo el subtítulo "La Sagrada Ceiba y el Aura Tiñosa" (1975: 113). 
"Despidiendo el duelo de Rosa Parks" existe ya la lluvia tras la reconciliación conseguida. En el mito ortodoxo, la lluvia vuelve cuando un aura tiñosa consigue llegar hasta el cielo. Los buitres aparecen en "Despidiendo el duelo de Rosa Parks" identificados con las mujeres negras. La voz poética explica que tiene la sensación de "vernos como las tiñosas cuando/ amenaza lluvia" (Herrera, 2006: 16). Estas aves, a pesar de ser consideradas como despreciables, habían sido las artífices de la reconciliación entre el cielo y la tierra, o entre blancos y negros, como lo hizo Rosa Parks y muchas mujeres cubanas en los años cincuenta y sesenta. Pero una vez que el objetivo se cumple, su contribución queda desestimada.

Georgina Herrera se inventa una continuación del mito del bien y del mal yoruba para contar lo que les pasó a las tiñosas, como mujeres negras cubanas, tras la llegada de la supuesta paz racial. Para ello, un salto temporal lleva a las tiñosas del mito hacia un presente donde la voz poética quiere volver a pedir ayuda al cielo para mejorar su situación. Sin embargo, esta vez, las tiñosas no pueden ser las mensajeras, debido a que ahora la lluvia les impide volar. El agua que había sido motivo en el pasado de alegría y victoria se torna en una amenaza en el presente:

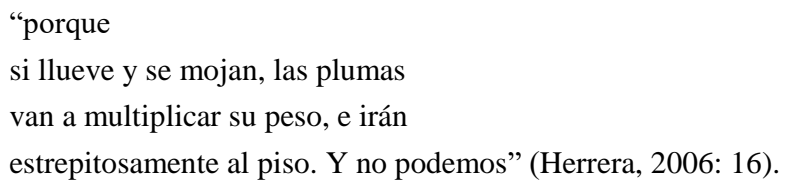

Ante la imposibilidad de volar, las tiñosas-mujeres negras envían al espíritu ligero de Rosa Parks para que hable con el cielo. En la tierra, quedan pendientes de los mensajes que les llegarán mediante la invocación espiritista:

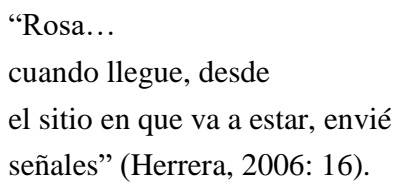

En el poemario aparecen otras mujeres negras, africanas y cubanas, que se han resistido a la esclavitud, a la colonización étnica, a la discriminación social y a la dominación patriarcal. En Golpeando la memoria Georgina Herrera explica el origen de algunos de los caracteres rebeldes y memorables que le han inspirado:

\begin{abstract}
"A veces, leyendo sobre lo que iba a escribir para ese programa ${ }^{22}$, llegaba la inspiración para un poema, así surgió "Canto de amor y respeto para doña Ana de Sousa", que tiene como tema algunos lugares de Angola y su gente. También escribí sobre Fermina Lucumí, la esclava dirigente de la primera sublevación organizada que hubo durante el periodo colonial, porque esas mujeres merecen ser enfocadas, reconocidas y recordadas" (Herrera y Rubiera, 2005: 106).
\end{abstract}

${ }^{22}$ Espacio radiofónico llamado Grandes momentos de la historia de Radio Progreso. 
De los dos poemas mencionados en esta cita, el de "Fermina Lucumí" está incluido en el poemario África (17). Como explica Catherine Davies, esta esclava llevaba un nombre sincrético que conectaba el español, Fermina, con el dado a los yorubas de Cuba, Lucumí (1993: 40). Fermina Lucumí aparece en tercera persona en el poema, como la protagonista de un relato oral. De ella se cuenta su participación en las revueltas de 1843 en Matanzas y su oposición al sistema. A la vez que este personaje histórico es recordado por su resistencia, también se alude a las memorias de África de la propia Fermina Lucumí, creando una cadena de recuerdos que conecta a la voz poética contemporánea con la vida de esta mujer en África, antes de ser esclavizada:

\author{
“¿Qué recuerdos \\ traídos desde la tierra en que era libre \\ como la luz y el trueno \\ dio la fuerza a su brazo?" (Herrera, 2006: 17).
}

La reminiscencia de una vida en libertad hace que la protagonista de este relato poetizado luche por recuperar su vida sin cadenas hasta "decapitar a su enemigo" (2006: 17). Ese mismo deseo es compartido por la voz poética que aspira a su liberación y le gusta imaginar los ojos de la esclava para ver en ellos la vitalidad que ella necesita: "Lástima que no exista una foto de sus ojos./ Habrán brillado tanto" (Ibídem: 17). Personajes históricos como Ana de Sousa, Fermina Lucumí o Rosa Parks se ven como una fuerza inspiradora de resistencia, de lucha y de cambio similar a la de la orisha Oyá, diosa de la guerra, de los truenos y de las tormentas. Georgina Herrera parece inspirarse de este ansia de liberación en su lucha por la descolonización de las prácticas religiosas de la mujer negra.

Aparte de las mujeres célebres por sus hazañas históricas, Georgina Herrera incluye también la rebeldía de los miembros femeninos de su familia, entre ellas la de sus tías Victoria y Sabina, cuyas hazañas quedan registradas en su testimonio (Herrera y Rubiera, 2005: 76). El poema "Retrato oral de Victoria" (Herrera, 2006: 6) está dedicado a la primera. Es muy breve y la idea básica es la transmisión del espíritu de resistencia de unas generaciones a otras, así como el orgullo de tal herencia que la voz poética muestra ante las circunstancias contemporáneas: "Dicen/ que me parezco a ella" (Ibídem). Esta rebeldía también aparece en "Oriki para mí misma" (Ibídem: 5), donde la voz poética es transgresora, rebelde y cimarrona, y vive en constante enfrentamiento contra aquellos que tratan de esclavizarla:

\footnotetext{
"Yo soy la fugitiva,

la que estruendosamente abrió

de par en par las puertas

de la casa-vivienda

'y cogió el monte"” (Herrera, 2006: 16).
} 
La primera persona de "Oriki para mí misma” aparece como una mujer anónima y no localizada en el tiempo, a diferencia de los datos históricos que Georgina Herrera incluye en el caso de otras mujeres negras. Al relatar la huida en pretérito, la voz poética podría reflejar a una mujer negra que vivió la época esclavista, o a una mujer actual que vivió una situación parecida, ya que la propia escritora se refiere en su testimonio a la violencia recibida de manos de su propio padre, situación de la que tuvo que escapar (Herrera y Rubiera, 2005: 27). El hecho de que la autora use gramaticalmente el presente para declarar que el sujeto poético es todavía "la fugitiva" parece una forma de conectar el tiempo contemporáneo con el pasado de esclavitud y la necesidad de seguir luchando hoy en día por la liberación de la mujer negra.

Todos estos últimos sujetos poéticos parecen vivir una eterna guerra, como Oyá. Esta orisha es también una divinidad fluvial, diosa del río Níger en África, que baña el territorio yoruba al norte y al este (Cros Sandobal, 1976: 204). Por eso, tras los enfrentamientos y las huidas, parece que la voz poética de "Oriki para mí misma" se reconforta y reconstituye con el agua sagrada: "Río/ otra vez mientras/ bebo el agua eternamente/ fresca de los curujeyes" (Herrera, 2006: 5). "Río" es una palabra polisémica. Por una parte, se podría relacionar con la acción de reír debida a la burla hacia el enemigo, por la otra, con el hecho de que Oyá es la diosa de su propio río africano. La referencia al agua sagrada en Cuba se hace al nombrar al curujey ${ }^{23}$. La voz poética calma su sed gracias a este agua purificadora y medicinal.

Otra orisha aludida con su río en el poemario es Ochún, la que popularmente se caracteriza por su dulzura y sensualidad, siendo asociada con la miel y las aguas dulces. En el poema dedicado a ella se habla del río africano que lleva su mismo nombre y que está localizado en la parte oriental del territorio yoruba. Este río es sumamente importante porque su corriente pasa por las cercanías de la ciudad sagrada Ilé Ifé, en Nigeria. De él surge uno de los peces mensajeros de la diosa: "Viene, desde el fondo del río con su nombre/ hasta la orilla" (Herrera, 2006: 9). El pez llega para cumplir su misión de tocar el rostro de una muchacha que se estremece al enamorarse:

\footnotetext{
"Que un pez del río Ochún la roce

es como untarse de miel y polvos de mil flores.

ella es la diosa del amor, su carne es vencedora

y basta" (Herrera, 2006: 9).
}

El problema surge cuando la joven se olvida de pedir protección a Ochún en la fiesta del amor: "No piensa la muchacha que, invocándola, / puede venir la paz y la abundancia" (Ibídem). Este olvido la lleva a ser abusada por su pareja, "el enemigo", el hombre patriarcal. La muchacha se ve cazada como una presa rodeada de "trampas tendidas entre los sembrados" (Ibídem). También aparece sometida mediante el miedo, cuyo temor se entrevé en la pregunta de estilo

\footnotetext{
${ }^{23}$ Nombre que se le da a la Tillandsia Recurvata, una planta medicinal que crece normalmente sobre las ceibas y que se caracteriza por almacenar agua de lluvia en la base de sus hojas.
} 
indirecto que hace la voz poética como si fuera la joven en cuestión: “QQuién se atrevía?" (Ibídem). En esta lucha, la muchacha deja atrás su hermosura: "Nadie recuerda, no sabe o no le importa/ el destino que entonces/ fijó la diosa a su belleza" (Herrera, 2006: 9).

El olvido es un tema muy importante en el poema. La muchacha no invoca a Ochún y, posteriormente, la sociedad no recuerda a la muchacha. Ella parece haber contribuido a la amnesia colectiva. Las razones nobles de su acto de amor se le han vuelto en contra: "Fue por bondad lo que se cuenta de otro modo/ con malicioso orgullo" (Ibídem) ${ }^{24}$. La mujer se ve triplemente silenciada por su raza, por su género y por su pobreza. Esta última opresión aparece con la alusión al hambre. Pero un cambio está por venir: frente a aquellos "tiempos feroces" (Ibídem) del ayer, y el olvido en que han caído tanto Ochún como la muchacha, la voz poética marca la diferencia con el "ahora" (Ibídem: 10). El presente es un tiempo en el que una nueva generación de mujeres va a recuperar la historia de la muchacha olvidada y le va a hacer justicia sin ella intuirlo siquiera: "no piensa / en que alguien, al menos, reconozca un día / (del que ya es tiempo) esta verdad" (Ibídem). La voz poética no sólo asume la misión de recuperar la historia de la muchacha, sino también la de la orisha, invocada mediante el título del poema.

La valoración de Ochún es muy importante porque su entidad divina tiene cualidades medicinales y curativas en torno a problemas causados por traumas físicos, espirituales y sicológicos. Entre otros métodos de sanación, se usan en su nombre las cualidades terapéuticas del agua (Olajubu, 2004: 51). Además de asociarse con la sensualidad, Ochún es la diosa del perdón y de la reconciliación y se la asocia con la espiritualidad y la paz. No hay que olvidar que es una de las orishas más invocadas en $\mathrm{Cuba}^{25}$. Restablecer el espacio de la muchacha y su dignidad se equipara a la acción de recuperar el espacio de ésta en el orden sagrado, como única manera de lograr la armonía. Oyeronke Olajubu recoge el odú original de la orisha Ochún en su libro Women in the Yoruba Religious Sphere:

"Al principio de los tiempos, Olodumare, el Ser Supremo, envió diecisiete divinidades primordiales para ocupar la tierra. Ochún era la única orisha femenina de los diecisiete. Por esta razón, a ella no se le permitió saber sobre las decisiones tomadas por las otras dieciséis divinidades primordiales. Cuando Ochún no pudo aguantar esta situación más, congregó a las mujeres en isalaye (la tierra), quienes intervinieron e hicieron que todas las deliberaciones de las divinidades fueran infructíferas. El resultado fue el caos total en cada esfera de la tierra. La situación fue más tarde remediada por la súplica a Ochún por parte de las otras dieciséis divinidades primordiales ${ }^{26}$ " (2003: 121).

\footnotetext{
${ }^{24}$ La bondad podría referirse a haber seguido el modelo mariano y los designios del hombre.

${ }^{25}$ Como explica Oyeronke Olajubu en Women in the Yoruba Religious Sphere, hay algunas deidades como Osanyín, Obatalá y Ochún que están asociadas con las hierbas y con las curaciones (2003: 111). Sobre las cualidades de Ochún escribe Tabaré Güerere Añez en Las diosas negras: la santería en femenino (1995: 6371).

26 "In the beginning of time, Olodumare the Supreme Being sent seventeen primordial divinities to occupy the earth. Osun was the only female of these seventeen. Because of this, she was excluded from knowing anything about decision taken by the other sixteen primordial divinities. When Osun could bear this no longer, she gathered together women in isalaye (earth) who intervened and made all the divinities
} 
Ochún debe ser respetada por los orishas masculinos. Si esto no ocurre se está atentando contra el orden divino. Dentro del discurso womanista, Georgina Herrera aboga por el respeto hacia la mujer por parte de los hombres de su comunidad, reivindicando su participación en la toma de decisiones del espacio sagrado, familiar y social.

De entre todas las orishas, la más adorada por la poeta es Yemayá (Zapata-Calle, 18-062013). Georgina Herrera establece como esenciales dos poemas para expresar su compromiso con la comunidad negra: "Primera vez ante un espejo" e "Ibu Sedi" (2004: 18). Este último es un poema dedicado a Omi Sande, la hija de Yemayá en la cosmología yoruba (Howe, 2003: 149). Si la escritora reclamaba en los años setenta el desarrollo de la maternidad humanizante, su reivindicación continúa décadas después. Hay que considerar que en Cuba, tras las políticas de distanciamiento familiar de las primeras décadas revolucionarias, se vuelve a reconocer políticamente la importancia de la función de la madre en la educación de los hijos. El Periodo Especial mostró que no sólo había una crisis económica, sino también cívica y moral, por lo que el gobierno vio la necesidad de potenciar el reforzamiento de los lazos familiares (Smith y Padula, 1996: 165-67). De esta manera, el discurso amoroso de la relación materno-filial de la poeta entra en el marco socio-político aceptado a partir de los años noventa.

El tema de la maternidad aparece en la última composición poética, "África" 27 (Herrera, 2006: 20-21), compartiendo el título del libro. La autora da un paso más en el desarrollo del tema al mostrarla en una dimensión espiritual, más que familiar. Para ello, África se sacraliza al ser el espacio original de ancestros y dioses y el continente se personifica en una mujer transformada en madre espiritual. La voz poética se siente hija de un África a la que ama y de cuyos dioses parece haber aprendido sus comportamientos:

\author{
"Amo a esos dioses \\ con historias así \\ como las mías: \\ yendo y viniendo \\ de la guerra al amor o lo contrario" (Ibídem: 21).
}

El legado africano recuperado en Cuba es visto como un niño frágil que necesita crecer $^{28}$. La voz poética ampara esta herencia con el cariño y la dedicación que un hijo requiere, y como

deliberations fruitless. The result was total chaos in every sphere of the earth. The situation was later remedied by pleas to Osun by the other sixteen primordial divinities" (Olajubu, 2003: 121).

${ }^{27}$ Este poema fue publicado anteriormente en Grande es el tiempo (1989) y se puede considerar como un poema womanista porque constituye la maduración del orgullo étnico, genérico y cultural de la mujer negra.

${ }^{28}$ Catherine Davies comenta el poema de "África" tomando elementos biográficos de la poeta. Lo compara con la relación de madre e hija que Georgina Herrera mantuvo con su hija Anaísa. Para Davies "la hija resulta representada por medio de África y África por medio de la hija, en términos de amor filial" (1999: 63). En esta lectura, sin embargo, se va más allá de los datos autobiográficos para ver la maternidad en un plano espiritual. 
una madre protectora repite el verso "yo te cuido" dos veces, una al principio y otra al final del poema, para que la idea de custodia amorosa lo envuelva ${ }^{29}$.

Para M. M. Adjarian, la voz narrativa de Cahier d'un retour au pays natal (1939), de Aimé Césaire, habla de su profundo deseo de restaurar el cordón umbilical del frágil esplendor del pasado, además de recuperar la imagen de unión de una madre y unos hijos separados y maltratados:

“[...] las islas desconectadas — una de las cuales es su tierra natal Martinica, podrían ser parte de una gran y unificada entidad [...] la madre ha sido separada de sus hijos isleños tanto en el tiempo como en el espacio. Todo lo que queda de ella son pequeños y rotos pedazos de tierra dispersos por el Caribe [...] para Césaire en particular, esas huellas contienen la memoria de las heridas hechas a su fuerte y montañoso cuerpo. La forma particular que las islas presentan son como "cicatrices" [...] sobre las aguas del Atlántico. Tal imagen trae a la mente las violaciones y genocidios de la otra madre (patria), actos que se originaban por la voluntad humana más que por las leyes naturales ${ }^{30}$ " (Adjarian, 2004: 12).

Tanto la madre África como los hijos isleños del Caribe han sido desconectados y debilitados, causándoles traumas que se han transmitido hasta el presente. La reunificación familiar parece necesaria para que se produzca la curación. Al producirse la unión materno-filial entre Cuba y África en el plano religioso, la voz poética siente haber encontrado el descanso y la paz: "Pienso en las aguas de tus ríos y quedan/ mis ojos lavados" (Herrera, 2006: 20).

Se podría decir que el sujeto poético de esta última composición es la hija de África, a la misma vez que es la madre de una nueva generación de cubanos que heredará el legado espiritual yoruba que ella custodia. De esta manera, tanto África como la Afro-Cuba, que representaría la voz poética, serían igualmente madres y se mirarían como imágenes reflejadas en un espejo, puesto que las dos parecen ser las responsables de cuidar de la herencia espiritual: "Este rostro, hecho / de tus raíces, vuélvese / espejo para que en él te veas" (Ibídem). El "tú" y el "yo" como madre e hija, marcan dos identidades diferentes pero conectadas, mirándose y protegiéndose mutuamente en una transmisión matrilineal.

La mujer negra cubana, amparada ya por su madre espiritual, recupera su status de persona con voluntad, con amor hacia sí misma y hacia sus divinidades. Una vez restablecida la relación entre África y Cuba con el proceso de yorubización womanista, después de un tiempo de

\footnotetext{
${ }^{29}$ El recurso del marco poético también existe entre el título del poemario y el título de su última composición lírica, "África”. La escritora parece impregnar el resto de poemas con la idea de la sacralidad del continente africano.

30 "the isolated islands — of which his Martiniquan homeland is one - could be part of a larger, unified entity $[\ldots]$ the mother is at a remove from her island offspring both in time and space. All that remains of her are broken bits of earth scattered across the Caribbean Sea [...] for Césaire in particular, those traces hold the memory of injuries done to her strong and mountainous body. The very form the islands take are like "cicatrices" [...] upon the waters of the Atlantic. Such a picture calls to mind the other mother(land)violating acts- genocide and rape - that had their origins in human agency rather than in the natural world" (Adjarian, 2004: 1-2).
} 
separación forzada, las mujeres negras cubanas que aparecen en la poesía de Georgina Herrera ya no se sienten desprotegidas o "en busca del árbol que las cobije" (Herrera, 2006: 16). Han encontrado finalmente en África, vista como una ceiba sagrada restablecida, la protección divina que necesitaban. África también les ofrece un modelo de mujer activo y luchador, a la misma vez que dulce y amoroso, en el que la mujer negra puede encontrar una manera de ser digna y libre. Es por ello que al final del libro la voz poética exclama: "Junto a ti permanezco, como al pie/ del más grande árbol" (África, 2006: 20).

Georgina Herrera trae a su poesía un mundo espiritual de una tradición centenaria, separada de la cristiandad, con mitos y divinidades universales. Esto es importante para las mujeres negras en cuanto a que se recuperan modelos de ser femeninos muy diferentes a los de la pasiva y sumisa Virgen María católica, a la vez que se libera del modelo patriarcal de las religiones sincréticas afrodescendientes que absorbieron el patriarcado religioso del catolicismo. Está claro que Georgina Herrera no sólo apoya el discurso de yorubización y neoafricanización de las prácticas religiosas, sino que también crea un espacio womanista en el campo espiritual que ayuda a la liberación de la mujer negra dentro y fuera de sus comunidades.

\section{BIBLIOGRAFÍA}

- Adjarian, Maude M. (2004): Allegories of Desire: Body, Nation, and Empire in Modern Caribbean Literature by Women. Westport, CT: Praeger.

- Argüelles Mederos, Aníbal (1998): "Expresiones religiosas de origen africano". En: Rosa Alfonso (ed.): Panorama de la religión en Cuba. La Habana: Editora Política, pp. 31-48.

- Ayorinde, Christine (2004): "Santería in Cuba: Tradition and Transformation". En: Toyin Falola and Matt D. Childs (eds.): The Yoruba Diaspora in the Atlantic World. Bloomington and Indianapolis: Indiana University P., pp 209-30.

- Barquet, Jesús, J. (2011): Ediciones El Puente en la Habana de los años 60. Chihuahua, México: Ediciones del Azar.

- Cimarroneando con G.H./ Cimarroneando with G.H (2011): Juanamaría Cordones-Cook [DVD]. Columbia, Missouri: Curators of the University of Missouri.

- Cordones-Cook, Juanamaría (2001): “Georgina Herrera: una cimarrona contemporánea”. En: Unión, vol. 73, pp. 72-80.

- Cros Sandoval, Mercedes (1975): La religión afrocubana. Lydia Cabrera (prol). Madrid: Plaza Mayor.

- Davies, Catherine (1993): "Writing the African Subject: The Work of Two Cuban Women Poets". En: Women: A Cultural Review, vol. 4, n. 1, pp. 32-48.

(1999): "Madre África y memoria cultural: Nancy Morejón, Georgina Herrera, Excilia

Saldaña". En: Revolución y cultura, vol. 2, n. 3, pp. 56-67. 
- Fernández Robaina, Tomás (2007): "Género y orientación sexual en la santería”. En: Cuba, personalidades en el debate racial (Conferencias y ensayos). La Habana: Editorial de Ciencias Sociales, pp. 187-201. . (2009): "La yorubización en el candomblé y en la santería". Identidad afrocubana, cultura y nacionalidad. Santiago de Cuba: Editorial Oriente, pp. 85-102.

- From maids to compañeras (1998): Jean Weisman [VHS]: LAVA.

- Güerere Añez, Tabaré (1995): Las diosas negras: la Santería en femenino. Caracas, Venezuela: Alfadil Ediciones.

- Herrera, Georgina (1962): GH. La Habana: Ediciones El Puente. . (2004): Gritos. Miami, Florida: Torre de Papel. . (2006): África. Matanzas: Ediciones Manglar y Uvero. (2010): Gatos y liebres o Libro de las conciliaciones. La Habana: Colección Contemporáneos, Ediciones Unión. . (2011): "Oriki por las negras viejas de antes". En: Daisy Rubiera Castillo e Inés Martiatu Terry (eds.): Afrocubanas: historia, pensamiento y prácticas culturales. La Habana: Editorial de Ciencias Sociales. 219-224.

- Herrera, Georgina y Daisy Rubiera Castillo (2005): Golpeando la memoria. La Habana, Cuba: Ediciones Unión.

- Howe, Linda S. (2003): “"The Lion's Version of the Jungle'. A Conversation with Georgina Herrera". En: Miriam DeCosta-Willis (ed.): Daughters of the Diaspora. Afra-Hispanic Writers. Miami: Ian Randle Publishers, pp. 145-156.

- Joyce, Joyce Ann (1999): “African-Center Womanism: Connecting Africa to the Diaspora”. En: Isidore Okpewho, Carole Boyce Davies, Ali Al'Amin Mazrui (eds): The African Diaspora: African Origins and New World Identities. Bloomington, IN: Indiana University Press, pp. 538554.

- Lahaye Guerra, Rosa María (2010): “¿Adiós al sincretismo? (Parte I y II)”. En: Blog Ifá Esbu Omó Iré. Disponible en: http://www.eshuomoire.com/adios-al-sincretismo/\#more-1002 [10/06/2016].

- McGuire, Danielle L. (2010): At the Dark End of the Street. New York: Vintage Books.

- Murrell, Nathaniel Samuel (2010): Afro-Caribbean Religions: An Introduction to Their Historical, Cultural, and sacred tradition. Philadelphia: Temple University P.

- Olajubu, Oyeronke (2003): Women in the Yoruba Religious Sphere. Albany: State University of New York P.

. (2004): “Seeing through a Woman's Eye: Yoruba Religious Tradition and Gender Relations”. En: Journal of Feminist Studies in Religion, vol. 20, nº. 1, pp. 41-60.

- Orozco, Roman y Natalia Bolivar (1998): Cubasanta: comunistas, santeros y cristianos en la isla de Fidel Castro. Madrid: El País-Aguilar. 
- Parés, Luis Nicolau (2004): “The 'Nagoization' Process in Bahian Candomblé". En: Toyin Falola and Matt D. Childs (eds.): The Yoruba Diaspora in the Atlantic World. Bloomington and Indianapolis: Indiana University P., pp. 185-208.

- Prados-Torreira, Teresa. Mambisas (2005): Rebel Women in Nineteenth-Century Cuba. Gainesville, FL: U Press of Florida.

- Rubiera Castillo, Daisy (1999): "La mujer en la Regla de Ocha. Una mirada de género". Revolución y Cultura, vol. 2, nº 3, pp. 72-75. . (2005): "Georgina Herrera: una poeta afrocubana". En: Afro-Hispanic Review, vol. 24, $\mathrm{n}^{\circ} .2$, pp. 127-136.

- Rubiera Castillo, Daisy y Herrera, Georgina (2005): Golpeando la memoria. La Habana, Cuba: Ediciones Unión.

- Rubiera Castillo, Daisy y Martiatu Terry, Inés (2011): Afrocubanas: historia, pensamiento y prácticas culturales. La Habana: Editorial de Ciencias Sociales.

- Smith, Lois M. and Alfred Padula (1996): Sex and Revolution: Women in Socialist Cuba. New York: Oxford University P.

- Zapata-Calle, Ana [Entrevista a Georgina Herrera (inédita)], La Habana, 18-06-2013.

- Zardoya Louredo, Rubén (1996): “Adiós al sincretismo: Minuta sobre la transculturación de la religión yoruba en Cuba". En: Tablas, vol. 4, pp. 4-6. 